\title{
Monetary Rewards and Competences of Young European Graduates
}

\author{
José-Ginés Mora \\ CEGES, Technical University of Valencia \\ Adela Garcia-Aracil \\ INGENIO, CSIC \\ José-Miguel Carot \\ Department of Statistics, Technical University of Valencia \\ Luis E. Vila \\ Department of Applied Economics, University of Valencia
}




\section{Introduction}

Competences, understood as those skills, talents and capabilities of higher education graduates that contribute to multi-factor productivity gains, are perceived as a key element for sustainable economic growth and development in the globalised economy (Romer, 1987; Hartog, 1992). Reviews of literature in both the research and policy arenas reveal that there is often little definitional and conceptual distinction between the terms competences and skills and that attributes often characterized as personal qualities also appear on list of competences (Weinert, 2001). In public discourse and sometimes also in specialized literature, there is a tendency to use terms such as skill, qualification, competence, and literacy, either imprecisely or interchangeably, in order to describe what individuals must learn, know, or be able to do to succeed in school, at the workplace, or in social life.

Education is widely considered an indispensable aspect of any and all conceptual and practical approaches to these issues, as evidenced by the everincreasing emphasis that is placed on education as a resource and asset for individual and social achievement (Belfied, Bullock and Fielding, 1999). With his heightened attention on education, tomorrow's curriculum has become a relevant topic for political discourse and education reform efforts all over the world. There is a growing concern among governments and the general public about the adequacy and quality of education and training, as well as the economic and social returns on public educational expenditures. From the society perspective, educational outcomes are seen as crucial factors for productivity and competitiveness (Buchel, 2002). The importance of worker quality, skills, and competences as key for survival and "the first strategic factor that can be used to boost productivity and market competitiveness" (Callieri, 2001) was underscored by various commentators from the business perspective (Farrugia, 2001; Oliva, 2003). Several approaches have emphasized competences via the perspective of a successful life and a well-functioning society, conceiving the potential societal benefits of a well-educated citizenry as including a productive economy, democratic processes, social cohesion, and peace. At the individual level, the potential benefits of competences entail successful participation in the labour market, in political processes, and in social networks; and meaningful 
interpersonal relations and general satisfaction with one's life (García-Aracil, Mora and Vila, 2004; Heijke, Meng and Ramaekers, 2002; Allen and Van der Velden, 2001).

In the last two decades, horizontal educational and professional mobility became more widespread among countries with similar qualities of the education system and with a similar stage of economic development. Scientific and technological progress, especially in the communications industry, have promoted international integration and cooperation but also intensified international competition. In order to develop quick responses to the challenges of this new order while safeguarding and improving their socio-economic standards, European countries have recognised knowledge as their most valuable resource for fuelling economic growth. Where people acquire knowledge, learn skills and transform them into competence for meaningful use, they not only stimulate economic and technological progress, but also derive much personal satisfaction and well-being from their endeavours.

Faced with EU enlargement, an ageing population, rising migration, increasingly complex career paths, consistently high levels of unemployment and the associated risk of social exclusion, European countries have started to take a closer look at those competences likely to be needed by adults in the future. European countries are increasingly concerned to identify the competences, skills, knowledge, abilities and attitudes that will equip their citizens to play an active part in this emerging knowledge-driven society. Efforts to determine the core attributes needed to participate effectively in political, economic, social and cultural activities are being pursued at national and international level (Rychen and Salganik, 2003). The relationship between competences and employment is not really clear. But clear is that there is a discrepancy between the acquisition of competences, e.g. during study, and the requirement of competences at a later time period, e.g. for professional work.

This paper contributes to the identification of a valuable set of key competences relevant to graduates' professional success. we try to gain into the following research questions: 
- $\quad$ To what extent education and training system have different patterns in European countries? To what extent are competences immutable with reference to social, economic, and cultural conditions? Are they generally valid from country to country?

- Which competences provide more monetary rewards in terms of income?

For that purpose, we used the multivariate correspondence analysis as a tool of data analysis presented in section 2 together with the data; section 3 presents the results, and section 4 provides conclusions and implications for policy matters.

\section{Methodology and data}

Correspondence analysis is a descriptive/exploratory technique designed to analyse simple two-way and multi-way tables containing some measure of correspondence between the rows and columns. These methods were originally developed primarily by Jean-Paul Benzerci in the early 1960's and 1970's (Benzerci, 1973). The results provide information, which is similar in nature to those produced by factor analysis techniques, and they allow one to explore the structure of categorical variables included in the table. In a typical correspondence analysis, a cross tabulation table of frequencies is first standardized, so that the relative frequencies across all cells sum to one. One way to state the goal of a typical analysis is to represent the entries in the table of relative frequencies in terms of the distances between individual rows and/or columns in a lowdimensional space.

Assuming the $k$-column values in each row of the table as coordinates in an $m$-dimensional space, we could compute the Euclidean distances between the $k$-row points in the $m$-dimensional space. The distances between the points in the $m$-dimensional space summarize all information about the similarities between the rows. Afterwards we hypothesize that we could find a lower-dimensional space, in which to position the row points in a manner that retains all, or almost all, of the information about the differences between the rows. We could then present all information about the similarities between the rows in a simple one, two, or $m$ dimensional graph. While this may not appear to be particularly useful for small 
tables, we can easily imagine how the presentation and interpretation of very large tables could greatly benefit from the simplification that can be achieved via correspondence analysis

A major difference between correspondence analysis and most other techniques for categorical data analysis lies in the use of models (Van der Heijden et al., 1989; Goodman, 1986). In correspondence analysis it is claimed that no underlying distribution has to be assumed and no model has to be hypothesized, but a decomposition of the data is obtained in order to study their "structure". However, conclusions about the data may not be generalized at population level as suggested by Greenacre (1984).

The data used in this research was taken from a major representative survey comparing the situation of graduates from higher education institutions. More than 36,000 graduates from twelve countries holding a higher education degree were surveyed four years after graduation (graduates from 1995 were surveyed in 1999). The study, named Careers after Higher Education - A European Research Survey (CHEERS), included graduates from Austria, the Czech Republic, Finland, France, Germany, Italy, the Netherlands, Norway, Spain, Sweden and the United Kingdom as well as Japan. From autumn 1998 to spring 2000, about 3,000 graduates each from 9 countries of the European Union, one EFTA country (Norway), one of the Central and Eastern European countries in transition (the Czech Republic) and one economically advanced country outside Europe (Japan) provided information through a written questionnaire on the relationship between higher education and employment four years after graduation. The respondents answered questions on their socio-biographic background, study paths, transition from higher education to employment, early career, links between study and employment, their job satisfaction and their retrospective view of higher education.

The CHEERS database addressed information with respect to 36 different items representing demands for and supplies of competences. Graduates were asked to indicate on an ordered scale ranking from 1 (not at all) to 5 (to a very high extent), the extent to which they had a given competence at time of graduation (the acquired level of competence) and the extent to which this given competence was required in their current work (the required level of competence). 
The acquired level of competences offers evidence about the graduates' selfassessment on the level of competences built up during one's higher education and the level of competences required offers self-report measures about graduates' immediate job situation. For a question of homogeneity we have considered only European countries as the whole sample. A description of the 36 items is shown in Annex 1.

The usual way to summarize such data is to count frequencies of response and present these in tables or in graphical form, usually bar or line charts. A second level of analysis is to explore relationships between different questions in the survey. Standard procedures are available when the questions involve quantitative responses, for example correlation-based methods such as regression analysis, principal component analysis and factor analysis. In our paper, in the case of categorical responses, the way to proceed is less obvious, which the level of acquired and required competence is a multicategorical variable having five possible responses, and different values in each of the eleven countries considered. Correspondence analysis is a method aimed specifically at quantifying categorical data, which is assigning numerical scale values to the response categories of discrete variables, with certain optimal properties. These scale values have been shown to have interesting geometric properties and provide what are called «maps» of the relationships between variables.

In this context, we aim to show how multivariate correspondence analysis can be used to describe the patterns of acquired and required competences among the following European countries: Italy, Spain, France, Austria, Germany, The Netherlands, United Kingdom, Finland, Sweden, Norway, Czech Republic.

Concerning about the field of study, graduates in a given field have similar life goals and job prospects, as well as a similar educational and social background, irrespective of cultural and labour market differences associated with their country of residence (García-Aracil et al, 2004). In this context, we map the relationship between the level of acquired and required competences according with the following field-study groups: Education, Humanities, Social Sciences, Law, Natural Sciences, Mathematics (which includes Computer Sciences), Engineering, Medical Sciences. 
Finally, we explore the relationship between the level of acquired and required competences and graduates' payoff both in terms of income (monetary rewards) and job satisfaction (which includes the non-monetary rewards as well).

\section{Results}

\subsection{Results by country}

The application of multiple correspondence analysis shows that 33 percent of the explanatory capacity of the model is due to the first axis (dimension 1) and 22 percent due to the second axis (dimension 2). A visualization of the results is presented in Figure 1. As we can see the profiles of acquired and required competences in the Mediterranean countries - Italy, Spain and France (group 1) and the rest of European countries - Austria, Germany, the Netherlands, United Kingdom, Finland, Sweden, Norway and Czech Republic (group 2) are different, as it was expected. The Mediterranean countries of our sample are characterised by the lack of competences related to the field-specific knowledge of methods (a4), computer skills (a6), understanding complex social, organisational and technical systems (a7), planning, co-ordinating and organising (a8), applying rules and regulations (a9), working under pressure (a17) and working independently (a23). However, it was exactly the opposite in the case of loyalty and integrity competence (a30). 
Figure 1. Correspondence analysis by country (dimension 1 and 2)

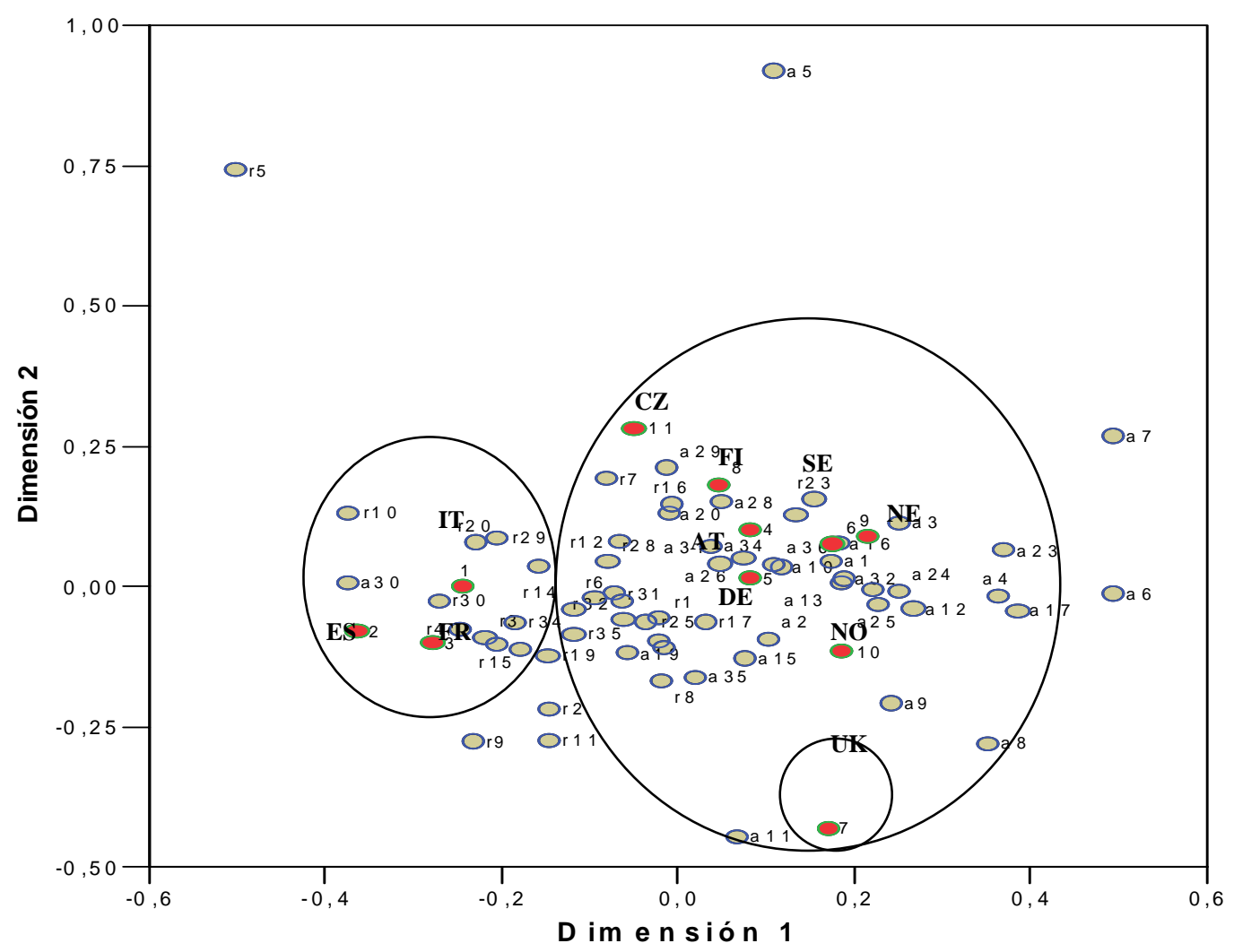

Looking at the plot of row and column points in Figure 1 with twodimensional space for the second group of European countries, one can observe that the United Kingdom has a more separate position defined by its closer vicinity to the competence of documenting ideas and information (a11) and the big distance to the competence related to foreign language proficiency (a5).

For a more detailed description, we plot (see Figure 2) the third and fourth dimension allowing us to explain 82 percent of the total capacity of the model (additional 16 percent is explained by the third dimension and 11 percent by the fourth dimension). 
Figure 2. Correspondence analysis by country (dimension 3 and 4)

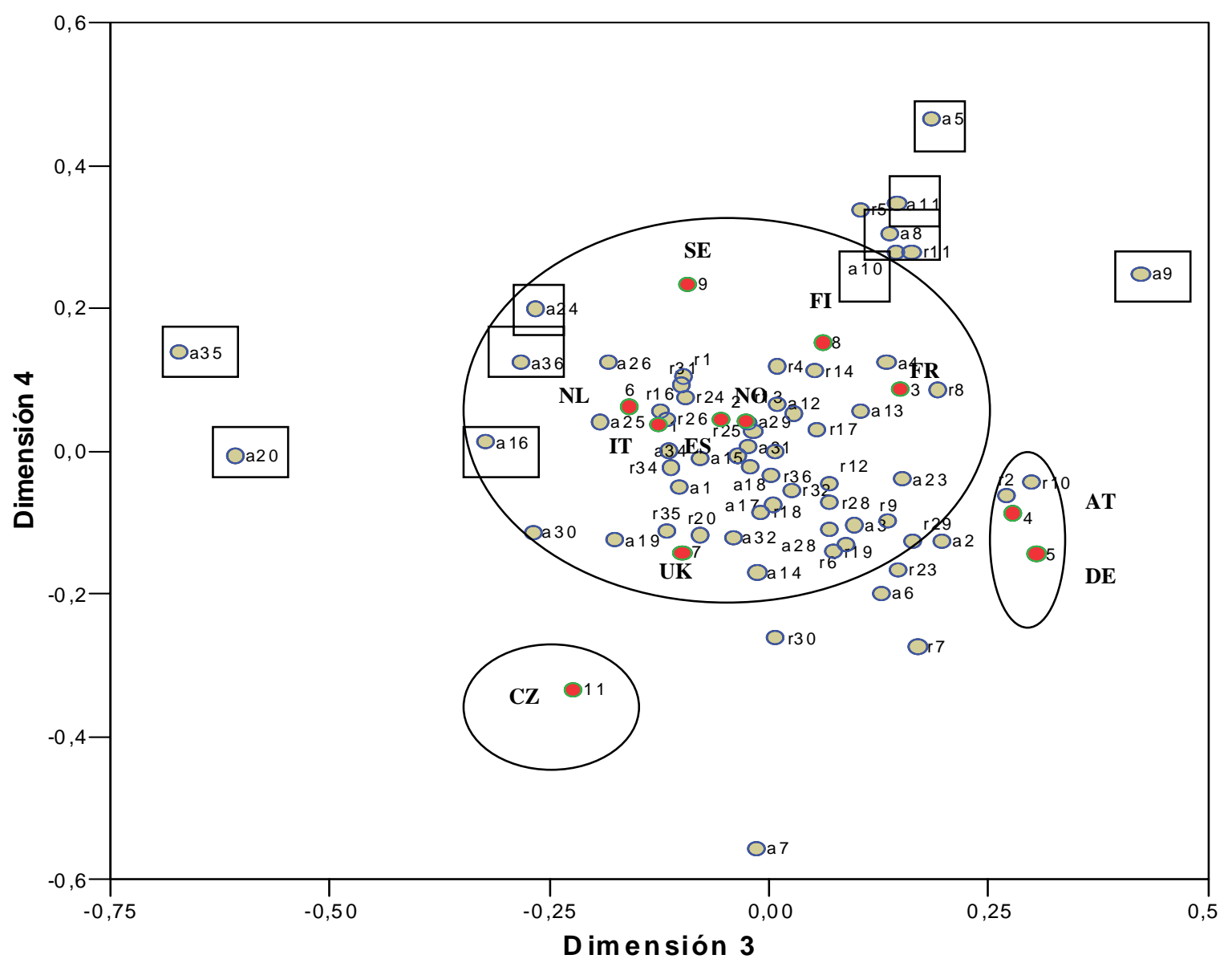

In Figure 2, we can appreciate that, on one hand, Austria and Germany are a new group and Czech Republic, on the other hand. With respect the overall level of competences acquired leadership (a35), negotiating (a20), working in a team (a24), creativity (a16), taken responsibilities, decisions (a36), and loyalty, integrity (a30) are less provided by the Austrian and German higher education system than the rest of European countries analysed. On the other hand, it could be said that the higher education system of Czech Republic provides on average less level of competences related to planning, co-ordinating and organising (a8), applying rules and regulations (a9) and documenting ideas and information (a11) compared to the rest of European countries in our analysis. 


\subsection{Results by level of annual gross income}

The multiple correspondence analysis applied to eight different levels of annual gross income is presented in Figure 5. In this case, we plot only twodimensional space, where 45 percent of the total inertia is explained by the first axis (dimension 1) and 20 percent by the second axis (dimension 2). A visualization of the row and column points allow us to define 5 different levelincome groups: the highest income group greater than 70 thousand of euro (group 1), 60-70 income group (group 2), 40-60 (group 3), 30-40 (group 4), and the lowest income group less than 30 thousand of euro (group 5).

A first relevant result is that the better paid group is related to a specific group of competences whereas the rest of groups have a similar structure in regard to competences. Results suggest that those jobs with higher requirement of working in a team (r24), getting personally involved (r29), understanding complex social, organisational and technical system ( $r 7)$, problem-solving ability (r12), oral communication skills ( $r 32)$, adaptability ( $(26)$, tolerance, appreciating of different points of view (r34), taken responsibilities and decisions ( $r 36$ ), leadership (r35) and written communication skills (r33) are the best paid. On the contrary, lower salaries are related to jobs with higher requirements of working under pressure (r17), reflective thinking, assessing one's own work (r15), analytical competences (r13) and loyalty, integrity (r30). 
Figure 5. Correspondence analysis by level of annual gross income

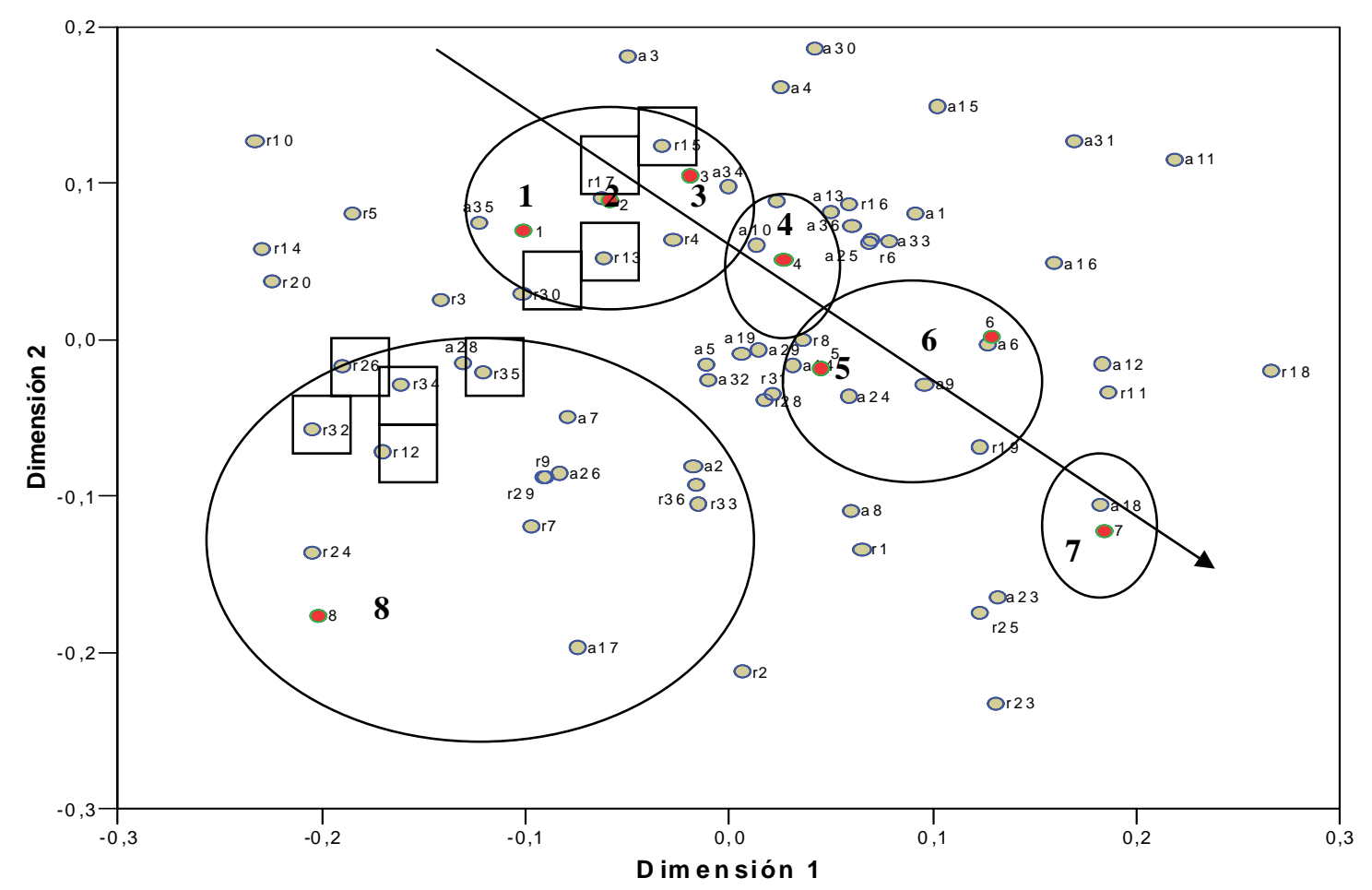

Note: annual gross income in thousand of euro $(1<10 ; 2=10-20 ; 3=20-30 ; 4=30-40 ; 5=40-50$; $6=50-60 ; 7=60-70 ; 8>70$ )

\section{Conclusions}

In this paper we have applied an exploratory methodology for analysing:

a) Whether exist a country or filed of study pattern in regard to competences;

b) The influence of required and acquired competences of European higher education graduates on the monetary benefits of education.

Results show that, at least in our sample, it does exist a specific pattern for countries in regard to the competences acquired by higher education graduates in the educational and training system. Based on this criteria European countries in our sample can be classified in Mediterranean (France, Italy and Spain), German (Germany and Austria) and Nordic (Sweden, Norway, Finland with the Netherlands), being the United Kingdom and the Czech Republic as independent cases. Each group is characterized by a closer relation to some type of acquired competences. For instance, the Mediterranean Group is characterized 
by lack of competences related to the field-specific knowledge of methods, computer skills, understanding complex social, organisational and technical systems, planning, co-ordinating and organising, applying rules and regulations, working under pressure, working independently. This suggests educational systems more theoretical oriented and lacked of connections with the reality of the labour market. The German Group is characterized by the lack of acquired competences in leadership, negotiating, working in a team, creativity, taken responsibilities, decisions, and loyalty, integrity. The Czech Republic is characterized by the lack of acquired competences related to planning, coordinating and organising, applying rules and regulations and documenting ideas and information. Finally, the United Kingdom is defined by a higher level of competence in documenting ideas and information and the lack of foreign language proficiency.

In regard to how competences are rewarded in monetary terms we have found a clear structure as well. The best paid graduates are those with positions where is relevant working in a team, getting personally involved, understanding complex social, organisational and technical system, problem-solving ability, oral communication skills, adaptability, tolerance, appreciating of different points of view, taken responsibilities and decisions, leadership and written communication skills.

This paper has also another result: the validity of the methodology that we have applied for differentiating a very complex set of variables and characteristics.

\section{References}

Allen, J. and Van der Velden, R. (2001): Educational Mismatches versus Skill Mismatches: Effects on Wages, Job Satisfaction and On-the-job Search, Oxford Economic Papers, 53(3): 434-452.

Belfield, C.R., Bullock, A.D. and Fielding, A. (1999): Graduates' Views on the Contribution of Their Higher Education to Their General Development: A Retrospective Evaluation for the United Kingdom, Research in Higher Education, 40(4): 409-438.

Benzecri, J.P. (1973): Analyse des Données, vols 1 and 2, Dunod. 
Buchel, F. (2002): The Effects of Overeducation on Productivity in Germany - The Firms' Viewpoint, Economics of Education Review, 21: 263-275.

Callieri, C. (2001): The Knowledge Economy: A Business Perspective, in D.S. Rychen and L.H. Salganik (eds.), Defining and Selecting Key Competencies, 228-231, Göttingen, Germany: Hogrefe and Huber.

Farrugia, J.P. (2001): Competence Management as an Investment: A Business Perspective, in D.S. Rychen and L.H. Salganik (eds.), Defining and Selecting Key Competencies, 232-235, Göttingen, Germany: Hogrefe and Huber.

García-Aracil, A., Gabaldón, D., Mora, J.G., Vila, L.E. (2004): The Relationship Between Life Goals and Fields of Study Among Young European Graduates, Higher Education (in press).

García-Aracil, A., Mora, J.G., Vila, L.E. (2004): The Rewards of Human Capital Competences for Young European Higher Education Graduates, Tertiary Education and Management (in press)

Goodman, L.A. (1986): Some Useful Extensions of the Usual Correspondence Analysis Approach and the Usual Log-linear Models Approach in the Analysis of Contingency Tables, International Statistics Review, 54:243309.

Greenacre, M.J. (1984): Theory and Applications of Correspondence Analysis, London, Academic Press.

Hartog, J. (1992): Capabilities, Allocation and Earnings, Kluwer, Boston.

Heijke, H., Meng, C. and Ramaekers, G. (2002): An Investigation into the Role of Human Capital Competences and Their Pay-Off, Research Memorandum, ROA, Maastricht.

Oliva, A. (2003): Key Competencies in and Across Social Fields: The Employers' Perspective, in D.S. Rychen, L.H. Salganik, and M.E. McLaughlin (eds.), 
Selected contributions to the $2^{\text {nd }}$ DeSeCo symposium, Neuchâtel, Switzerland: Swiss Federal Statistical Office.

Romer, P. M. (1987): Growth Based on Increasing Returns due to Specialization, American Economic Review, 77: 56-62.

Rychen, D.S., Salganik, L.H. (2003): Key Competencies for a Successful Life and a Well-Functioning Society, in Hogrefe and Huber (eds.), Cambridge, USA.

Van der Heijden, P., De Falguerolles, A, De Leeuw, J. (1989): A Combined Approach to Contingency Table Analysis Using Correspondence Analysis and Log-linear Analysis, Applied Statistics, 38: 249-292.

Weinert, F.E. (2001): Concept of Competence: A Conceptual Clarification, in D.S. Rychen and L.H. Salganik (eds.), Defining and selecting key competencies, 45-65, Göttingen, Germany: Hogrefe and Huber. 


\section{Annex 1}

Table A1. Descriptive Statistics for Competences.

\begin{tabular}{|c|c|c|c|c|}
\hline Items & \multicolumn{2}{|c|}{ Acquired } & \multicolumn{2}{|c|}{ Required } \\
\hline & Mean & Std. Dev. & Mean & Std. Dev. \\
\hline 1. Broad general knowledge & 3.70 & 0.82 & 3.62 & 1.00 \\
\hline 2. Cross-disciplinary thinking/knowledge & 3.39 & 0.88 & 3.65 & 1.01 \\
\hline 3. Field-specific theoretical knowledge & 3.82 & 0.93 & 3.68 & 1.13 \\
\hline 4. Field-specific knowledge of methods & 3.41 & 1.00 & 3.67 & 1.14 \\
\hline 5. Foreign language proficiency & 3.06 & 1.11 & 2.90 & 1.38 \\
\hline 6. Computer skills & 2.97 & 1.14 & 3.80 & 1.12 \\
\hline 7. Understanding complex soc., org. and tech. systems & 2.79 & 1.02 & 3.32 & 1.17 \\
\hline 8. Planning, coordinating and organising & 3.11 & 1.05 & 4.11 & 0.95 \\
\hline 9. Applying rules and regulations & 2.95 & 1.09 & 3.59 & 1.12 \\
\hline 10. Economic reasoning & 2.75 & 1.14 & 3.50 & 1.20 \\
\hline 11. Documenting ideas and information & 3.28 & 1.05 & 3.81 & 1.05 \\
\hline 12. Problem-solving ability & 3.62 & 0.90 & 4.30 & 0.79 \\
\hline 13. Analytical competences & 3.68 & 0.91 & 3.95 & 0.96 \\
\hline 14. Learning abilities & 4.18 & 0.76 & 4.03 & 0.90 \\
\hline 15. Reflective thinking, assessing one's own work & 3.52 & 0.94 & 3.95 & 0.91 \\
\hline 16. Creativity & 3.38 & 1.04 & 3.72 & 1.09 \\
\hline 17. Working under pressure & 3.53 & 1.08 & 4.29 & 0.89 \\
\hline 18. Accuracy, attention to detail & 3.70 & 0.98 & 4.14 & 0.86 \\
\hline 19. Time management & 3.30 & 1.04 & 4.14 & 0.87 \\
\hline 20. Negotiating & 2.58 & 1.05 & 3.66 & 1.15 \\
\hline 21. Fitness for work & 3.62 & 1.06 & 3.90 & 1.04 \\
\hline 22. Manual skills & 2.96 & 1.21 & 2.88 & 1.34 \\
\hline 23. Working independently & 3.95 & 0.95 & 4.33 & 0.86 \\
\hline 24. Working in a team & 3.65 & 1.04 & 4.19 & 0.93 \\
\hline 25. Initiative & 3.51 & 0.98 & 4.11 & 0.89 \\
\hline 26. Adaptability & 3.74 & 0.94 & 4.11 & 0.83 \\
\hline 27. Assertiveness, decisiveness, persistence & 3.50 & 0.99 & 4.14 & 0.84 \\
\hline 28. Power of concentration & 3.95 & 0.85 & 4.05 & 0.84 \\
\hline 29. Getting personally involved & 3.79 & 0.96 & 4.07 & 0.92 \\
\hline 30. Loyalty, integrity & 3.83 & 1.05 & 4.06 & 0.93 \\
\hline 31. Critical thinking & 3.76 & 0.94 & 3.90 & 0.96 \\
\hline 32. Oral communication skills & 3.62 & 0.99 & 4.30 & 0.83 \\
\hline 33. Written communication skills & 3.85 & 0.90 & 4.06 & 0.96 \\
\hline 34. Tolerance, appreciating of different points of view & 3.70 & 0.95 & 3.96 & 0.92 \\
\hline 35. Leadership & 2.83 & 1.06 & 3.57 & 1.14 \\
\hline 36. Taking responsibilities, decisions & 3.38 & 1.02 & 4.23 & 0.88 \\
\hline
\end{tabular}

